\title{
Anthropogenic impacts on heavy metal concentrations in the coastal sediments of Dumai, Indonesia
}

\begin{abstract}
Concentrations of $\mathrm{Cd}, \mathrm{Cu}, \mathrm{Pb}, \mathrm{Zn}, \mathrm{Ni}$ and $\mathrm{Fe}$ were determined in the surface sediments to investigate the distributions, concentrations and the pollution status of heavy metals in Dumai coastal waters. Sediment samples from 23 stations, representing 5 different site groups of eastern, central and western Dumai and southern and northern Rupat Island, were collected in May 2005. The results showed that heavy metal concentrations (in microg/g dry weight; $\mathrm{Fe}$ in \%) were 0.88 (0.46-1.89); 6.08 (1.61-13.84); 32.34 (14.63-84.90); 53.89 (31.49-87.11); 11.48 (7.26-19.97) and 3.01 (2.10-3.92) for $\mathrm{Cd}, \mathrm{Cu}, \mathrm{Pb}, \mathrm{Zn}, \mathrm{Ni}$ and $\mathrm{Fe}$, respectively. Generally, metal concentrations in the coastal sediments near Dumai city center (eastern and central Dumai) which have more anthropogenic activities were higher than those at other stations. Average concentration of $\mathrm{Cd}$ in the eastern Dumai was slightly higher than effective range low (ERL) but still below effective range medium (ERM) value established by Long et al. (Environmental Management 19(1):81-97, 1995; Environmental Toxicology Chemistry 17(4):714-727, 1997). All other metals were still below ERL and ERM. Calculated enrichment factor (EF), especially for $\mathrm{Cd}$ and $\mathrm{Pb}$, and the Pollution load index (PLI) value in the eastern Dumai were also higher than other sites. Cd showed higher EF when compared to other metals. Geo-accumulation indices ( $($ geo $)$ ) in most of the stations (all site groups) were categorized as class 1 (unpolluted to moderately polluted environment) and only $\mathrm{Cd}$ in Cargo Port was in class 2 (moderately polluted). Heavy metal concentrations found in the present study were comparable to other regions of the world and based on the calculated indices it can be classified as unpolluted to moderately polluted coastal environment.
\end{abstract}

Keyword: Heavy metals; Enrichment factor; Pollution index; Sediment; Indonesia 